\title{
Levantamento da Produção Científica Mundial e Ibérica no Campo dos Nanotubos de Carbono
}

\author{
Ricardo Silva ${ }^{1}$, Margarida Amaral ${ }^{2,3}$, Diogo Mata ${ }^{1,4}$, \\ Rui F. Silva ${ }^{1,4}$, Pedro M. F. J. Costa ${ }^{1,4,}$,
}

Os nanotubos de carbono (CNTs) são estruturas alongadas e monoelementares de dimensões nanométricas e com elevado potencial científico-tecnológico. Enquadrados na classe dos nanomaterais, tem-se verificado um enorme interesse pelo seu estudo desde a sua (re)descoberta em 1991 [1].

Neste trabalho, procedeu-se a um levantamento das publicações científicas e patentes relacionadas com CNTs a nível mundial com o intuito de compreender o volume de trabalho efectuado em quase duas décadas de investigação. Juntamente, analisou-se qual a situação presente em Portugal a este respeito. Como termo comparativo regional, escolheu-se Espanha, o país geograficamente mais próximo e possivelmente mais relevante no que toca a colaborações e investimento conjunto em Investigação e Desenvolvimento (I\&D).

Verifica-se que em Portugal a investigação científica em CNTs se encontra bastante aquém da tendência internacional e nitidamente menos desenvolvida do que no país vizinho. Neste, em conformidade com a situação mundial, tem-se registado um volume de trabalho crescente e de carácter progressivo desde 1994, o qual culminou recentemente com a atribuição de diversas patentes.

\section{INTRODUÇ̃̃o}

A descoberta dos CNTs encontra-se envolvida em controvérsia [2]. Todavia, desde o artigo fundamental de Sumio lijima [1] que os CNTs têm instigado globalmente uma enorme curiosidade em químicos, bioquímicos, físicos, engenheiros, etc. Muito desse interesse advém das características únicas destes alótropos de carbono os quais apresentam propriedades excepcionais ao nível electrónico, óptico, mecânico e térmico [3].

Estruturalmente, a rede cristalina dos CNTs é exclusivamente composta por ligações carbono-carbono envolvendo hibridações do tipo $\mathrm{sp}^{2}$. Sendo constituídos por uma ou mais folhas de grafeno enroladas, apresentam uma estrutura tubular de cilindros concêntricos com espaçamento entre si de $\sim 3,4$ A. Os CNTs são bastante resistentes a ataques químicos e apresentam uma estabilidade estrutural

Departamento de Engenharia de Cerâmica e Vidro, Universidade de Aveiro, 3810-193 Aveiro

Departamento de Física, Universidade de Aveiro, 3810-193 Aveiro

3N, Universidade de Aveiro, 3810-193 Aveiro * email: pedromfjcosta@ua.pt notável quando sujeitos a condições adversas de pressão, temperatura ou irradiação com feixes de partículas altamente energéticas [3]. No que se refere às suas propriedades eléctricas, elas podem variar, pois, consoante a forma como a folha de grafeno é enrolada, estes podem ter um carácter metálico ou semicondutor (de particular relevância para os CNTs com uma ou duas folhas). As suas propriedades mecânicas são também causa de grande interesse. Por exemplo, embora tenham uma elevada tensão de ruptura de $\sim 63 \mathrm{GPa}$ (50 vezes maior que a do aço), os nanotubos de folha simples (SWCNTs) são flexíveis (suportam uma notável deformação elástica, i.e. com recuperação da forma inicial) e possuem um elevado módulo de Young ( 1 TPa) [3]. Para além destas características intrínsecas, estes nanotubos são bastante versáteis podendo ser usados, por exemplo, como moldes para cristais de reduzida dimensão [4].

O presente trabalho surgiu da necessidade de conhecer o panorama nacional da I\&D em CNTs. Neste âmbito, os volumes de produção científica em
Portugal foram enquadrados tendo como referência, em particular, a produção espanhola e, em geral, a produção mundial.

\section{Metodologia}

O levantamento das publicações científicas e patentes relacionadas com nanotubos de carbono foi realizado recorrendo à base de dados electrónica ISI Web of Knowledge (WoK) [5] e utilizando como palavra-chave "carbon nanotube*", onde * é uma wildcard que representa qualquer letra ou grupo de letras. A palavra-chave foi introduzida no campo "Topic" para as publicações e no campo "Title" para as patentes. Na questão das patentes, esta pesquisa foi também efectuada no portal Free Patents Online [6] com o objectivo de confirmar os resultados obtidos com a WoK- Derwent Innovations Index. O estudo incidiu sobre vários critérios nos quais se incluem ano de publicação, autores, citações, país e/ou instituição de origem. No caso da literatura científica contabilizaram-se tanto as publicações regulares em jornais científicos (artigos) como aquelas derivadas de comunicações em con- 
gressos (proceedings) incluídas na Web of Science (base de dados integrada na WoK). Para as patentes, no caso mundial, contabilizaram-se todas aquelas identificadas pela WoK e seguidamente confirmadas na Free $\mathrm{Pa}$ tents Online. No que respeita aos casos específicos de Portugal e Espanha a busca restringiu-se apenas àquelas para as quais a instituição detentora da patente se encontrava sediada nestes países. Para tal foi necessário utilizar um filtro adicional (campo "Patent Number" $=E^{*}$ ou $\mathrm{PT}^{*}$ ).

O presente texto encontra-se dividido em duas categorias: a primeira refere-se ao panorama mundial, englobando tanto a produção de literatura científica como de patentes; na segunda parte, incluíram-se os dados respeitantes a Portugal e Espanha. Os resultados são apresentados sob a forma de gráficos ou tabelas.

\section{Resultados e Discussão}

\section{Produção Científica Mundial}

\section{Literatura (artigos e proceedings)}

Considera-se que os nanotubos de carbono foram parcialmente responsáveis por desencadear a revolução Nanotecnológica nos anos de 1990 [7]. De facto, desde o estudo de lijima [1], o campo dos CNTs desenvolveu-se de tal maneira que estes se tornaram num dos materiais mais intensamente estudados pela Ciência. Este fenomenal empenho é claramente demonstrado pelo número crescente de publicações científicas produzidas anualmente desde 1991 (Fig. 1). No

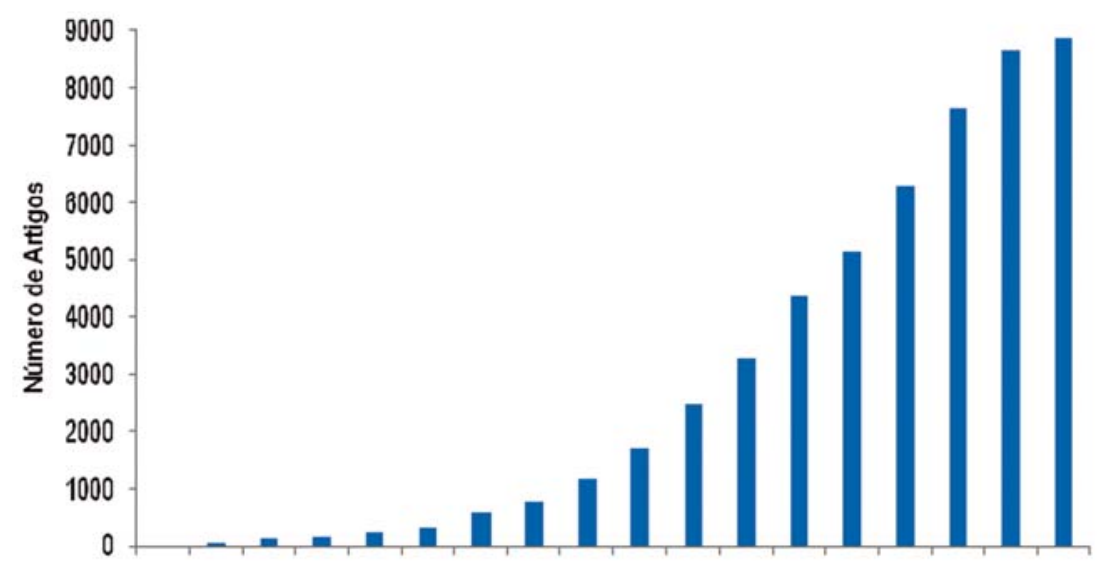

199219931994189519961997198819992000200120022003200420052006200720082009

Ano de Publicação

Figura 1 Evolução do número de publicações científicas relacionadas com CNTs. Pesquisa realizada à data de 16/01/2010 intervalo de 1991 a 2009, o cumulativo dos estudos em CNTs perfaz um total de mais de 50000 artigos e actas de conferências (proceedings). Um tal volume de literatura produzido em tão reduzido intervalo de tempo é inaudito para materiais de carbono e extremamente raro para qualquer outra substância.

Segundo os dados apresentados na Fig. 1, o empenho dos investigadores não esmoreceu ainda apesar do enorme volume de trabalho já efectuado. Usualmente tem-se representado a génese e evolução de novas tecnologias (ou ideias) como seguindo uma tendência de interesse e desenvolvi- mento caracterizada por uma curva em S, tal como é ilustrado na Fig. 2 (em inglês). Comparando esta curva com os dados extraídos da WoK, verifica-se que o reconhecimento do potencial destas nanoestruturas terá ocorrido por volta do ano 2000. Neste momento, e face ao crescimento contínuo observado, o campo permanece na rampa de elevada progressão científica. No entanto, considerando a descoberta do grafeno em 2004, é possível que brevemente os CNTs entrem num estágio de maturidade (à semelhança do que aconteceu com o campo dos fulerenos com a descoberta dos nanotubos).

\section{THE LIFE TRAJECTORY OF A TECHNOLOGICAL REVOLUTION}

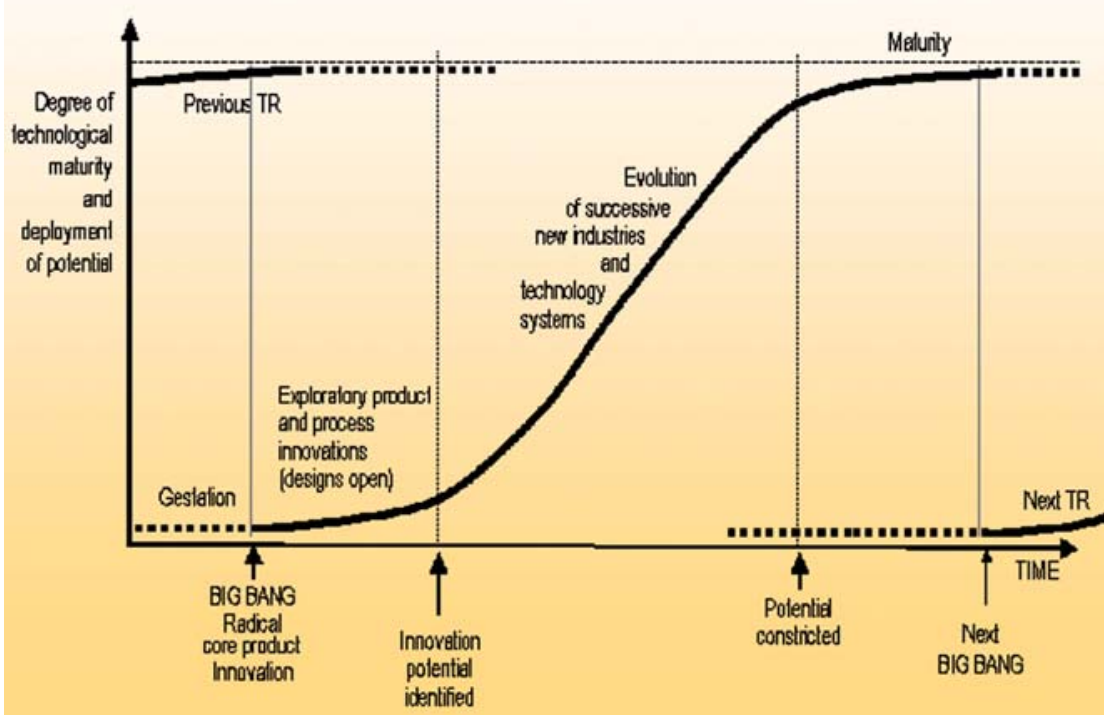

Figura 2 Gráfico característico do ciclo de vida de uma revolução tecnológica. Retirado de http://www.oxfamblogs.org/fp2p/?cat=58 à data de 02/12/2009

Face à elevada quantidade de publicações do campo, é pertinente averiguar quais as que se destacam. O impacto de uma publicação pode ser avaliado pelo número de vezes que é referida por outros artigos e proceedings (citações). Assim, no culminar de quase duas décadas de esforço internacional, aparecem vários trabalhos que se distinguem pela sua repercussão. Os dez estudos-chave do campo dos CNTs (top-10) encontram-se listados na Tabela 1. Excepcionalmente, a procura pela palavra-chave "carbon nanotube*" não identificou o artigo de Sumio lijima datado de 1991. Tal facto é justificado por a denominação "nanotubos de carbono" ter surgido na literatura apenas a partir de 1992 
[8]. Examinando o disposto na Tabela 1 , verifica-se que o artigo pioneiro de lijima (1991) apresenta mais de 9000 citações, sensivelmente 3 vezes mais que o segundo classificado. Em comparação, o artigo de H. W. Kroto et al. [9], que revelou a existência dos fulerenos $\left(\mathrm{C}_{60}\right)$ e pelo qual esta equipa recebeu o Prémio Nobel de Química em 1996, tinha um total de 6643 citações à data de 16 de Janeiro de 2010. É também interessante o número reduzido de jornais presentes na lista. O domínio avassalador das revistas Nature e Science confirma o impacto que estes periódicos têm no processo de desenvolvimento da Ciência. mente como um dos motores mundiais deste campo de I\&D. De facto, se adicionarmos o volume de trabalho produzido na Formosa (a qual a R. P. China encara como parte integrante do seu território) então a produção de literatura científica fica quase igualada à dos EUA. Admirável também que o México, país com pouca tradição em I\&D, nomeadamente em materiais de carbono, apareça neste lote. Uma possível justificação prende-se com a presença de algumas equipas de renome mundial tais como as dirigidas pelos irmãos Terrones no IPICYT. Portugal, com o dobro da população de Singapura e com um produto interno

Tabela 1 As dez publicações científicas mais citadas, a nível mundial, no campo dos CNTs. Pesquisa realizada à data de 16/01/2010

\begin{tabular}{|c|c|c|}
\hline Citações & Autores & Referência \\
\hline 9098 & S. lijima et al. & Nature 354 (1991), 56 \\
\hline 2995 & A. Thess et al. & Science 273 (1996), 483 \\
\hline 2672 & S. J. Trans et al. & Nature 393 (1998), 49 \\
\hline 2611 & R. H. Baughman et al. & Science 297 (2002), 787 \\
\hline 2283 & J. Kong et al. & Science 287 (2000), 622 \\
\hline 2055 & S. lijima et al. & Nature 363 (1993), 603 \\
\hline 1910 & A. C. Dillon et al. & Nature 386 (1997), 377 \\
\hline 1884 & W. A. Deheer et al. & Science 270 (1995), 1179 \\
\hline 1853 & M. M. J. Treacy et al. & Nature 381 (1996), 678 \\
\hline 1814 & E. W. Wong et al. & Science 277 (1997), 1971 \\
\hline
\end{tabular}

Numa época caracterizada pela procura incessante de Conhecimento e Inovação, onde as actividades de I\&D são extremamente competitivas e globais, pretendeu-se conhecer quais os países e regiões mundiais que maior empenho têm demonstrado na progressão do campo dos CNTs. Segundo os dados da Fig. 3, os EUA, com mais de 14500 artigos e proceedings, são responsáveis pela maior fatia do trabalho científico. Bastante próxima, a República Popular da China conta com mais de 11000 publicações. Segue-lhes, em terceiro lugar, o Japão com vários milhares de estudos. Curiosamente, neste top-20 encontram-se países tão diversos como a Coreia do Sul e o México. O volume de trabalho realizado em Portugal foi também incluído de forma a facilitar a leitura comparativa com o resto do mundo. Em particular, a posição da R. $P$. China é bastante interessante. Não sendo um país com tanta tradição de produção de Conhecimento como os EUA ou o Japão, revela-se actual-
Se estendermos a pesquisa anterior e agruparmos os países por continentes, verifica-se que é na Ásia que se encontra o grosso do trabalho realizado até hoje (Fig. 4). A Europa (onde se inclui a Rússia) aproxima-se do volume de publicações das Américas (Norte, Central e Sul) mas ambas ficam notavelmente atrás do esforço asiático. De novo, este é um dado interessante visto que até há relativamente pouco tempo apenas o Japão era encarado como um país produtor de I\&D em todo o continente asiático.

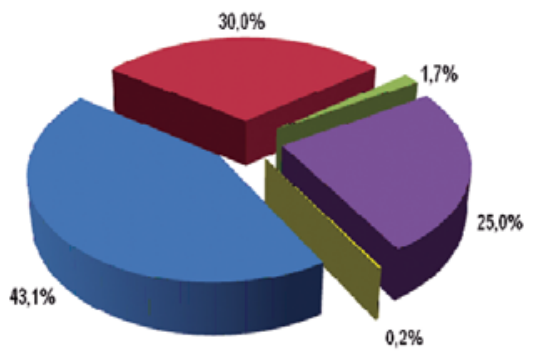

"Asia $\|$ Américas $=$ Oceania $\|$ Europa $\#$ Áfica

Figura 4 Distribuição da literatura científica sobre CNTs por continentes. Pesquisa realizada à data de $16 / 01 / 2010$

Tendo em conta a disparidade observada entre o país com maior número de publicações e a região planetária mais produtiva, é pertinente fazer uma busca sobre as instituições por detrás deste esforço internacional. Desta forma, descobre-se que, apesar da liderança dos EUA, a Chinese Academy of Science (CAS) é a instituição que mais publicou até hoje (Fig. 5). Demonstrando um desenvolvimento ímpar neste campo, destaca-se visivel-

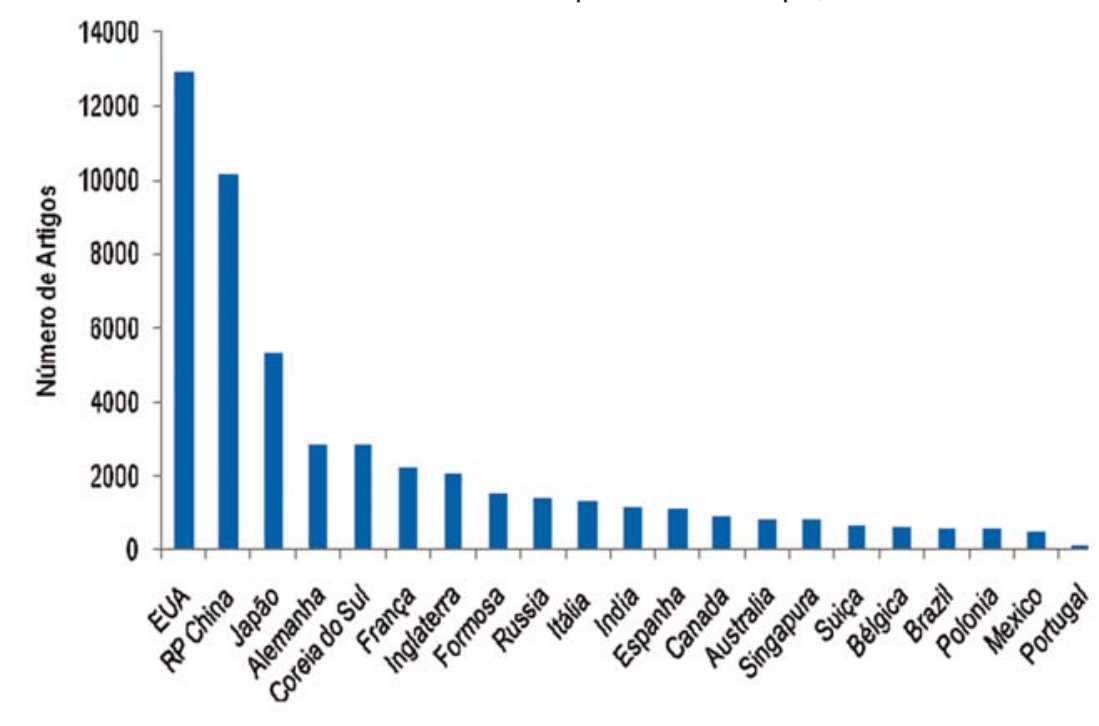

Pais

Figura 3 Publicações científicas relacionadas com CNTs distribuídas por país (top-20 mundial + Portugal). Pesquisa realizada à data de 16/01/2010 
mente de qualquer outra instituição. Todavia, é necessário alertar para as diferenças entre os vários tipos de instituições presentes nesta lista. A CAS é, na realidade, constituída por mais de cem institutos de investigação, uma universidade e uma escola de pós-graduação. Os seus recursos humanos, que incluem milhares de investigadores doutorados, são muitíssimo mais extensos do que a média das universidades. Numa situação semeIhante estão outras instituições, também elas redes nacionais de laboratórios, como sejam a Russian Academy of Science (RAS), o Centre National de la Recherche Scientifique (CNRS) e a National Aeronautics and Space Administration (NASA). Surpreendente é, de facto, como existem universidades que, porventura com dotações orçamentais mais reduzidas, conseguem competir com estas redes de laboratórios. No top-5 das instituições aparecem assim três universidades. Destas, a Tsing Hua University, localizada em Pequim, aparece à frente de duas das mais conceituadas instituições académicas dos EUA, a Rice University e o Massachusetts Institute of Technology (MIT). públicos os detalhes referentes à invenção, bem como as suas reivindicações em matéria de I\&D. A protecção de uma invenção através de patentes transforma-a num bem negociável não só para instituições académicas como para empresas. Desta maneira, a transferência de tecnologia sob a forma de licenças proporciona ganhos financeiros, o que incentiva a busca
De acordo com a Fig. 6, o número de patentes registadas mundialmente $\mathrm{e}$ cujo título contém "carbon nanotube*" conheceu um crescimento notório a partir de 1999. A este respeito é notável o incremento de mais de $75 \%$ na comparação das patentes relativas ao ano de 2007 (746) com aquelas de 2009 (1317). Cumulativamente, encontram-se 5688 registos de pa-

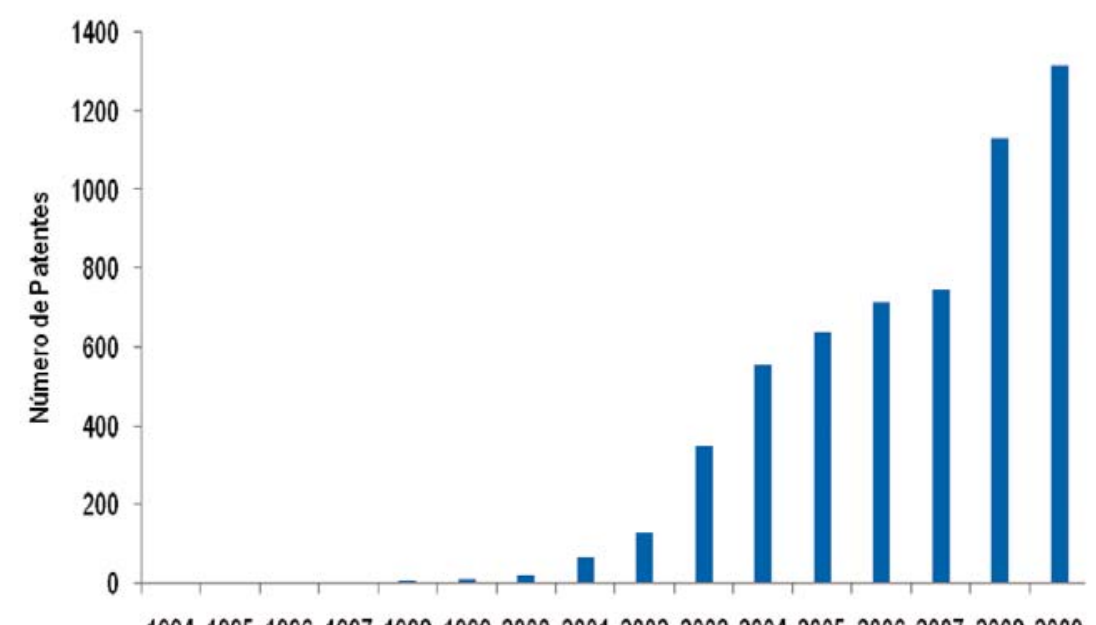

1994199519961997199819992000200120022003200420052006200720082009

Ano

Figura 6 Evolução do número de patentes relacionadas com CNTs. Pesquisa realizada à data de 16/01/2010

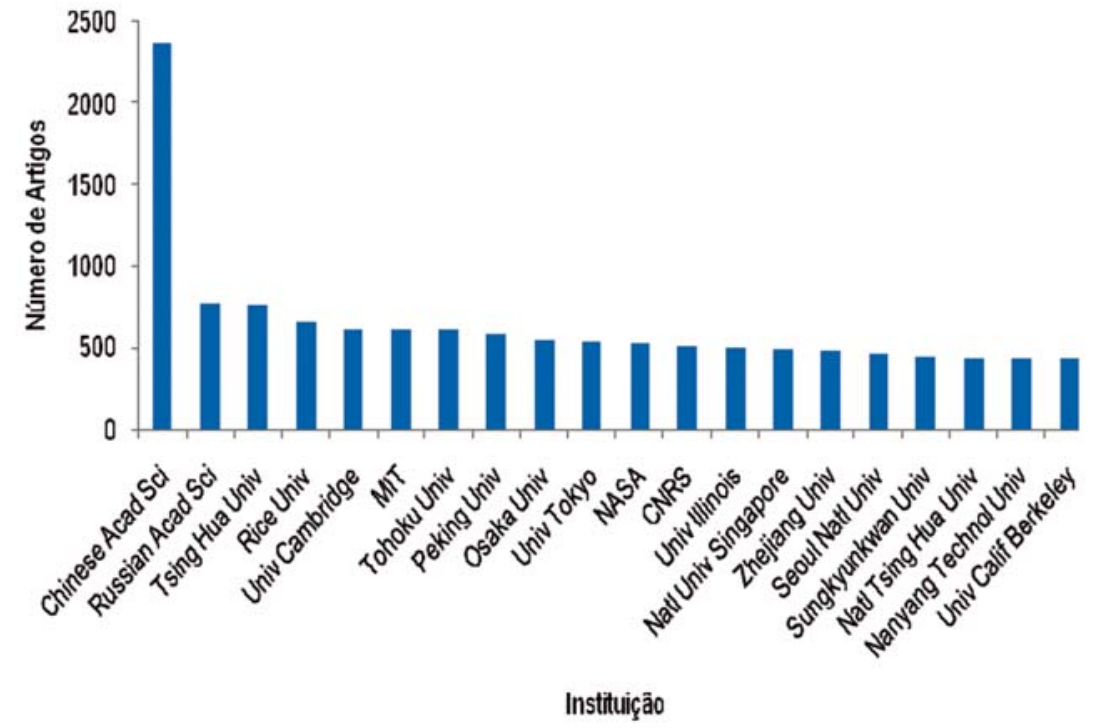

Figura 5 Publicações científicas relacionadas com CNTs ordenadas por instituição. Pesquisa à data de 16/01/2010

\section{Patentes}

Uma patente é um documento oficial emitido por um Estado soberano que reconhece, temporariamente, um conjunto de direitos exlusivos aos inventores (e demais titulares) de um novo produto ou criação. Em troca, o detentor da patente deve tornar progressiva de novas aplicações para materiais como os CNTs. Face ao volume de trabalho realizado ao longo das duas últimas décadas, o interesse em assegurar a propriedade intelectual das aplicações de CNTs tem também crescido. tentes relacionadas com CNTs nas bases de dados utilizadas. Note-se que foram necessários apenas 3 anos desde a publicação do primeiro artigo de CNTs para surgirem os primeiros registos de patentes (JP6280116-A, JP2845675-B2 e US5346683-A). O início da corrida de propriedade intelectual deu-se através do Gas Research Institute (US) e da NEC (JP). A forma célere como aparecem estas primeiras patentes ilustra bem como houve uma aposta nas potencialidades deste campo logo desde o seu início. Todavia, foram necessários mais de 7 anos para se consolidar esta corrida. Assim, apenas a partir de 1998 se encontra uma progressão constante de registos de patentes. Tal poderá resultar da evolução de uma área científica de alto impacto ser inicialmente dominada por questões de Ciência fundamental. Este ímpeto de propriedade intelectual mereceu a atenção de Baughman et al. num artigo publicado em 2002 [10]. Neste estudo foi sugerida a divisão das patentes então registadas nas áreas referidas na Fig. 7. Todavia, os autores 
advertiram que esta classificação era necessariamente subjectiva e portanto deveria funcionar apenas como um guia. Dado o grande número de patentes registadas desde este estudo e os erros que uma análise deste género comportaria, a actualização deste gráfico não foi realizada. adicional resulta das diferentes designações para a mesma instituição: o National Institute of Advanced Science and Technology do Japão (AIST), aparece seja em inglês, seja na designação em japonês (Dokuritsu Gyosei Hojin Sangyo Gijutsuso). Refira-se ainda que a Intel, um outro colosso

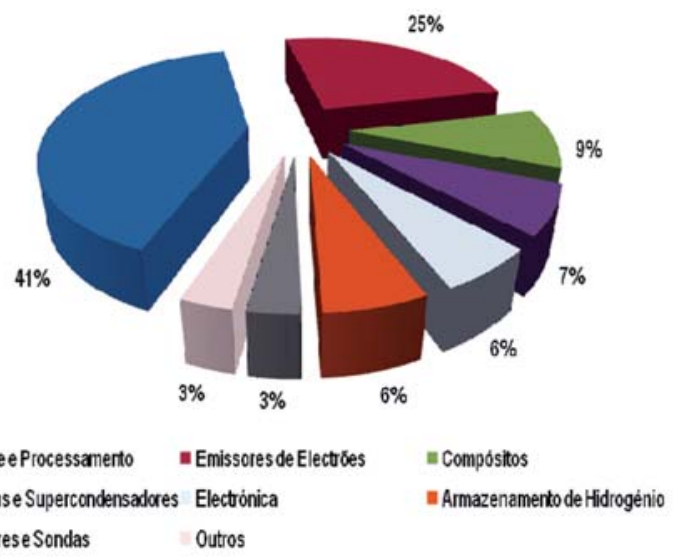

Figura 7 Principais áreas de registo de patentes relacionadas com CNTs (adaptado de [10])

No exame do panorama internacional de registo de patentes é também relevante tentar perceber quais os principais intervenientes neste campo. Por conseguinte, foi efectuada uma pesquisa de patentes por instituição detentora. $\mathrm{O}$ resultado, apresentado na Fig. 8, contém algumas surpresas. De facto, a principal detentora de propriedade intelectual relacionada com CNTs a nível mundial é a Foxconn, com 438 registos. Embora desconhecido do grande público ocidental, Foxconn é o nome comercial de um conglomerado formado por diversas empresas chinesas a principal das quais é a Hon Hai Precision Industries Company Ltd. Com sede na Formosa, a Foxconn é o maior produtor mundial de componentes electrónicos e informáticos sendo responsável pelo fabrico (e por vezes desenvolvimento) de produtos tão diversos como os telemóveis de última geração iPhone (Apple) ou as consolas de jogos Wii (Nintendo), Xbox 360 (Microsoft) e PlayStation (Sony). A segunda classificada é a multinacional sul-coreana Samsung, também ela um gigante mundial da electrónica, com 299 patentes. Refira-se que tanto para a Foxconn como para a Samsung foi necessário adicionar as patentes de cada uma das suas subsidiárias (por exemplo, Samsung Sdi Co Ltd, Samsung Electronics Co Ltd e Samsung Denkan KK). Um problema da electrónica e informática mundial, é a única empresa ocidental do top-10 , embora bastante distanciada das duas primeiras classificadas.

Finalmente, importa referir a presença das duas únicas instituições académicas no top-10 mundial: a Universidade de Tsing Hua e a Rice University. Relativamente à primeira, e em consonância com a produção de literatura científica (terceira classificada mundialmente), a Tsing Hua (por vezes referida localmente como o "MIT" chinês) regista um impressionante volume de propriedade intelectual. Para tal poderá ter contribuído a constituição do Tsinghua-Foxconn Nanotechnology Research Center em 2007, o qual alberga várias equipas dedicadas exclusivamente ao estudo de CNTs. De qualquer forma, neste top-10 mundial é visível o domínio das companhias multinacionais com sede no continente asiático, o que mais uma vez corrobora a forte influência da Ásia no campo dos nanotubos de carbono.

\section{Produção Científica Ibérica}

Na sequência dos resultados anteriores pretendeu-se verificar se a situação em Portugal seguia a tendência global. Todavia, uma vez que por questões várias é difícil relacionar directamente o trabalho nacional com o mundial, tentou-se encontrar um outro termo de comparação que pudesse oferecer uma visão mais localizada. Por essa razão, escolheu-se o país vizinho, a Espanha. Nas seguintes secções apresentar-se-ão os dados extraídos da WoK relativos à evolução do estudo de CNTs na Península Ibérica.

\section{Literatura (artigos e proceedings)}

Previamente, no gráfico da Fig. 3, observou-se que a Espanha tinha um volume de literatura científica produzido no intervalo de 1991 a 2009 maior que o de Portugal. Analisando agora em detalhe este resultado, tal como ilustrado na Fig. 9, verifica-se que em Espanha tem ocorrido um crescimento progressivo do estudo de CNTs desde 1994, 3 anos após a sua descoberta. Contrariamente, Portugal apresenta

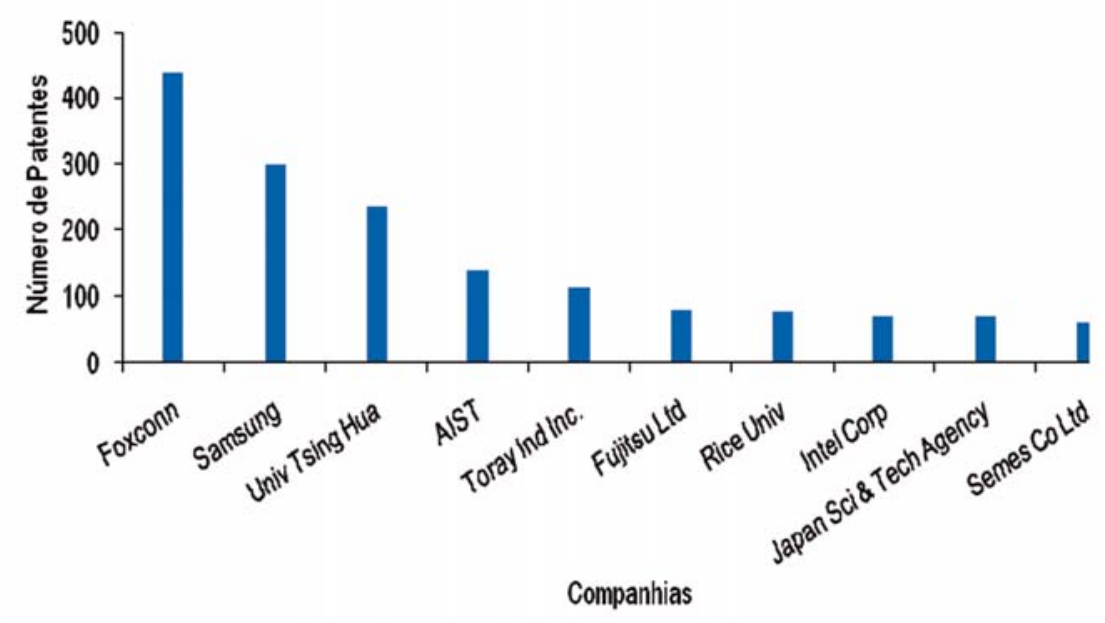

Figura 8 Top-10 mundial do registo de patentes relacionadas com CNTs. Pesquisa realizada à data de 16/01/2010 
um número incipiente e irregular de publicações neste intervalo de tempo. A manifesta diferença entre os dois países poderá sobrevir das dimensões e maturidade das respectivas comunidades científicas.

Todavia no biénio de 2008-09 parece finalmente ter surgido uma alteração deste panorama com recordes sucessivos de publicações em Portugal (33 em 2008 e 41 em 2009). Não obstante, a irregularidade passada e o arranque tardio poderão denotar uma incapacidade para o nosso país se posicionar rapidamente em novos campos de Ciência. Seria porventura interessante verificar se esta tendência também se aplica a outros campos surgidos na última década.

Tal como efectuado anteriormente, o passo seguinte foi descobrir quais as instituições que mais contribuíram para o esforço ibérico. Neste caso, as instituições foram organizadas por país e são apresentadas em separado.

Assim, no caso de Espanha, o gráfico de barras da Fig. 10, mostra que o Consejo Superior de Investigaciones Científicas (CSIC) se destaca visivelmente. Refira-se que, à semelhança do CNRS ou da CAS, esta organização é constituída por uma rede de laboratórios de investigação distribuídos por todo o território espanhol, o que justificará a enorme diferença observada.

No caso das outras instituições, a produção é semelhante sendo que apenas a Universidade Autónoma de Madrid ultrapassou a fasquia da centena de estudos até ao presente.

Dos estudos publicados em Espanha, foi averiguado quais os de maior impacto.

A Tabela 2 apresenta não só a referência mas também o título das publicações. Invulgarmente, observa-se que o top-5 das citações é constituído maioritariamente por publicações relativas a estudos de carácter téorico. Em três destas, são co-autores A. Rubio e P. Ordejon, possivelmente os investigadores mais influentes do campo em Espanha.

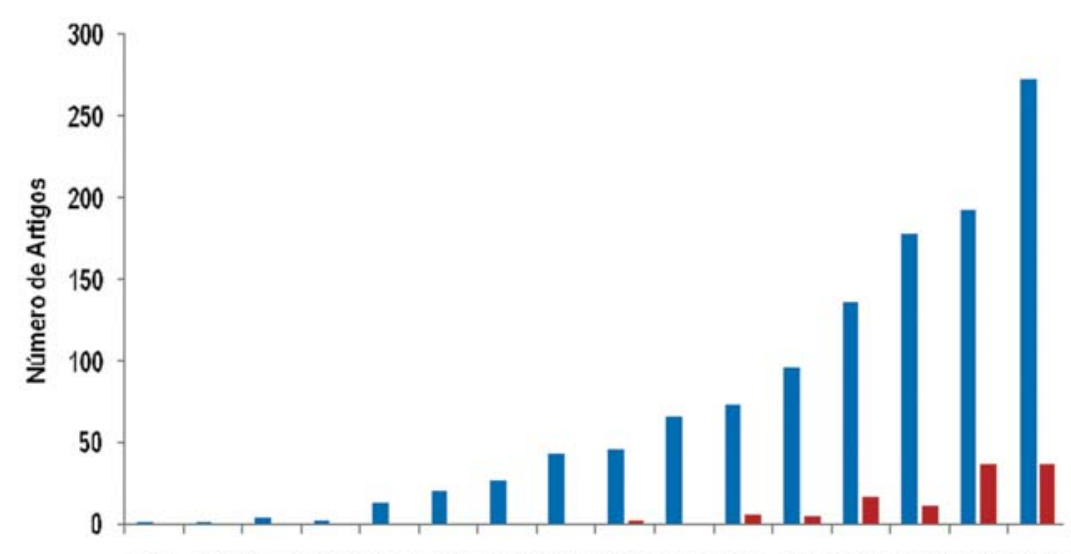

1994198519961997199819992000200120022003200420052006200720082009

\section{Ano}

Figura 9 Evolução do número de publicações científicas relacionadas com CNTs no período de 1991 a 2009, em Espanha (a azul) e Portugal (a vermelho). Pesquisa realizada à data de 16/01/2010

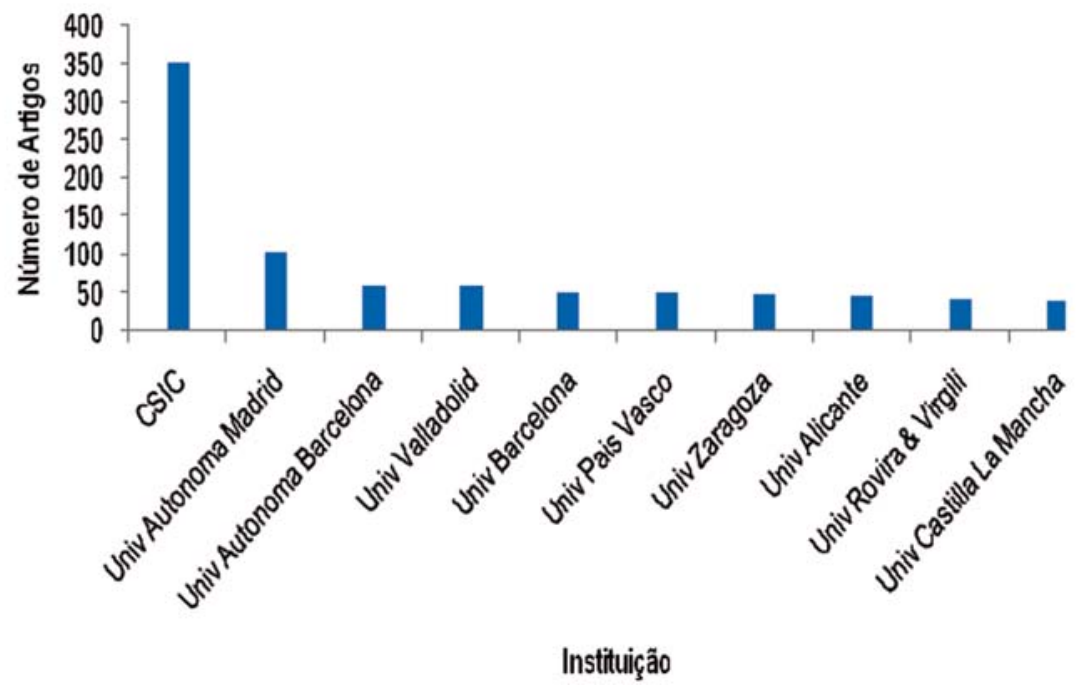

Figura 10 Distribuição das publicações científicas relacionadas com CNTs produzidas em Espanha por instituição. Pesquisa realizada à data de 16/01/2010

Tabela 2 Top-5 das publicações científicas mais citadas com (co-)autoria em Espanha. Pesquisa realizada à data de 16/01/2010

\begin{tabular}{|c|c|c|c|}
\hline Cit. & Autores & Título & Referência \\
\hline 661 & M. Brandbyge et al. & $\begin{array}{l}\text { Density functional method for non- } \\
\text {-equilibrium electron transport }\end{array}$ & $\begin{array}{c}\text { Phys. Rev. B } 65 \text { (2002) } \\
1098\end{array}$ \\
\hline 546 & P. M. Ajayan et al. & $\begin{array}{l}\text { Single-walled carbon nanotube- } \\
\text {-polymer composites: strength and } \\
\text { weakness }\end{array}$ & $\begin{array}{l}\text { Adv. Mater. } 12 \text { (2000) } \\
750\end{array}$ \\
\hline 526 & E. Hernandez et al. & $\begin{array}{l}\text { Elastic properties of } \mathrm{C} \text { and } \mathrm{Bx} C \mathrm{CyNz} \\
\text { composite nanotubes }\end{array}$ & $\begin{array}{l}\text { Phys. Rev. Lett. } 80 \text { (1998) } \\
4502\end{array}$ \\
\hline 427 & E. Artacho et al. & $\begin{array}{l}\text { Linear-scaling ab initio calculations } \\
\text { for large and complex systems }\end{array}$ & $\begin{array}{l}\text { Phys. Stat. Sol. B } 215 \\
\text { (1999) } 809\end{array}$ \\
\hline 401 & D. Sanchez-Portal et al. & $\begin{array}{c}\text { Ab initio structural, elastic, and } \\
\text { vibrational properties of carbon } \\
\text { nanotubes }\end{array}$ & $\begin{array}{c}\text { Phys. Rev. B } 59 \text { (1999) } \\
12678\end{array}$ \\
\hline
\end{tabular}


No que se refere à produção de literatura científica em Portugal, a distribuição por instituição revela que o panorama nacional é bastante equilibrado (Fig. 11).

Por um lado, no sistema científico nacional não existem organismos como o CSIC ou o CNRS. Por outro, o reduzido volume de trabalho traduz uma provável ausência de grupos de investigação exclusivamente dedicados a este tema. De qualquer forma, o esforço realizado até hoje provém essencialmente das regiões Centro e Norte.

Das publicações com origem em Portugal, o top-5 ordenado por citações é constituído exclusivamente por estudos de carácter experimental, tal como referenciado na Tabela 3. É importante também mencionar que a primeira alusão a CNTs num trabalho português data de 1996 e teve origem na Universidade do Porto [11].

\section{Patentes}

O estudo das patentes com origem na Península Ibérica revelou um cenário algo desolador. De facto, apenas foram encontrados quatro registos, todos provindos de Espanha (ver Tabela 4). Para um cumulativo que ultrapassa o milhar de publicações em Espanha, a reduzida dimensão e novidade destes registos (datados de 2008 e 2009) deriva talvez do carácter de investigação feita (teórico em detrimento do experimental).

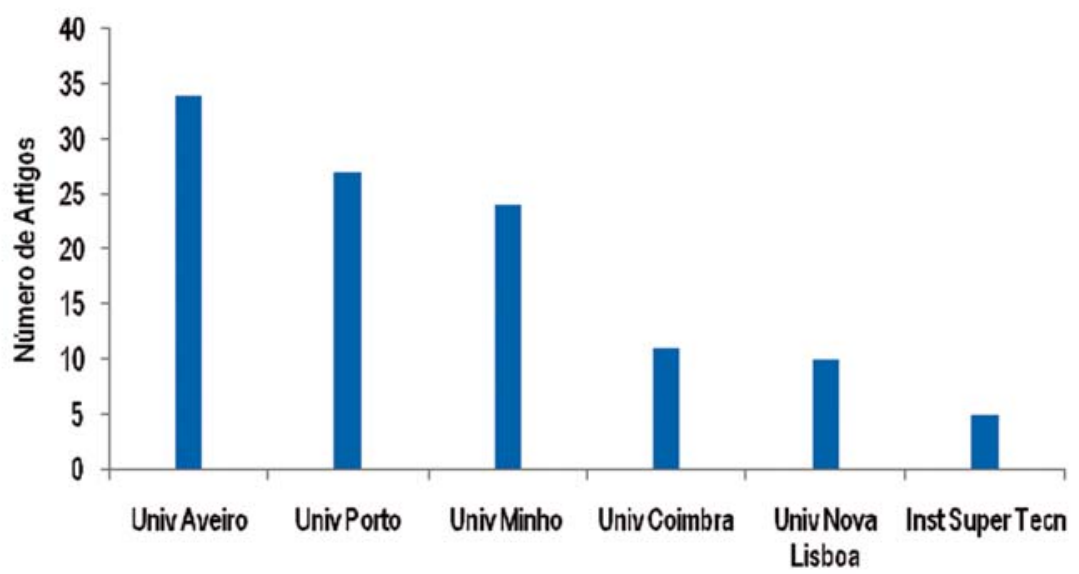

Instituiçāo

Figura 11 Distribuição de estudos sobre CNTs com (co-)autoria em Portugal por instituição. Pesquisa realizada à data de 16/01/2010

Tabela 3 Top-5 dos estudos sobre CNTs mais citados com (co-)autoria portuguesa. Pesquisa realizada à data de 16/01/2010

\begin{tabular}{|c|c|c|c|}
\hline Cit. & Autores & Título & Referência \\
\hline 149 & J. J. Davis et al. & The immobilization of proteins in carbon \\
nanotubes & $\begin{array}{c}\text { Inorg. Chim. Acta 272 } \\
\text { (2849) 261 }\end{array}$ \\
\hline 57 & M. C. Paiva et al. & $\begin{array}{c}\text { Mechanical and morphological } \\
\text { characterization of polymer-carbon } \\
\text { nanocomposites from functionalized carbon } \\
\text { nanotubes }\end{array}$ & Carbon 42 (2004) 2849 \\
\hline 46 & C. Baleizão et al. Wang et al. & $\begin{array}{c}\text { Photocatalytic degradation of phenol on } \\
\text { MWNT and titania composite catalysts by a } \\
\text { modified sol-gel method }\end{array}$ & $\begin{array}{c}\text { App. Catal. B 56 (2005) } \\
305\end{array}$ \\
\hline 46 & $\begin{array}{c}\text { Chiral vanadyl salen anchored on support as } \\
\text { recoverable catalysts for the enantioselective } \\
\text { cyanonglation of aldehydes. Comparison } \\
\text { activated carbon and imidazolium ion as } \\
\text { support }\end{array}$ & Tetrah. Lett. 60 (2004) \\
C. Baleizão et al. & $\begin{array}{r}\text { Vanadyl salen complexes covalenty } \\
\text { anchored to single-walled carbon nanotubes } \\
\text { as heterogeneous catalysts for the } \\
\text { cyanosilylation of aldehydes }\end{array}$ & J. Catal. 221 (2004) 77 \\
\hline
\end{tabular}

\section{Conclusão}

Tabela 4 Patentes relacionados com CNTs cujo detentor tem sede em Espanha. Pesquisa realizada à data de 16/01/2010. *Palavra-chave excepcionalmente introduzida no campo "Topic"

\begin{tabular}{|c|c|c|c|c|}
\hline ano & Autores & Detentor & Título & Registo \\
\hline 2009 & $\begin{array}{l}\text { M. Cabanillas } \\
\text { P. Lopez } \\
\text { M. Miranda }\end{array}$ & CSIC & $\begin{array}{l}\text { Dense and homogeneous ceramic } \\
\text { material consisting of carbon/silicon } \\
\text { nitride nanotubes, production method } \\
\text { and applications thereof. }\end{array}$ & ES000845 \\
\hline 2009 & $\begin{array}{l}\text { R. Quesada } \\
\text { C. Fernandez } \\
\text { A. Coll } \\
\text { C. Horna }\end{array}$ & CSIC & $\begin{array}{l}\text { Method for defining and producing } \\
\text { reactive chemical nanometric surface } \\
\text { patterns by means of gaseous-phase } \\
\text { soft lithography, resulting patterns and } \\
\text { devices and uses thereof. }\end{array}$ & ES000221 \\
\hline 2008 & $\begin{array}{l}\text { F. Ferrus } \\
\text { S. Aparicio } \\
\text { G. Paravano } \\
\text { J. Rusell }\end{array}$ & $\begin{array}{l}\text { Univ. Rovira I } \\
\text { Virgili }\end{array}$ & $\begin{array}{l}\text { Electrodes selective for solid-contact ions } \\
\text { based on carbon nanotubes. }\end{array}$ & ES001468 \\
\hline 2008* & $\begin{array}{l}\text { A. Marco } \\
\text { R. Villoria }\end{array}$ & $\begin{array}{l}\text { A. Marco } \\
\text { R. Villoria }\end{array}$ & $\begin{array}{l}\text { Nanoreinforcement prepreg method and } \\
\text { product thus obtained. }\end{array}$ & ES001515 \\
\hline
\end{tabular}

Pelo descrito acima conclui-se que, nas últimas duas décadas, tem-se registado um aumento progressivo da investigação relacionada com nanotubos de carbono ao nível mundial. Esta tendência é seguida por Espanha, mas não se reflecte ainda no nosso país. De facto, Portugal apresenta níveis incipientes de produção de trabalho científico em CNTs até ao presente.

No que respeita a propriedade intelectual, e em particular o registo de patentes, a situação mundial parece seguir a produção de literatura científica. Nos registos encontra-se uma forte predominância de companhias 
asiáticas, o que concorre com o domínio deste continente na produção de ciência relacionada com estas nanoestruturas. Finalmente, o registo de patentes na Península Ibérica afigura-se mínimo, sendo mesmo nulo em Portugal.

Não é do âmbito deste estudo investigar os factores que contribuíram para este desfasamento de Portugal com o resto do mundo, mas seria porventura de interesse verificar se esta situação seestendea outros campos da Ciência.

\section{REFERÊNCIAS}

[1] S. lijima, Nature 354 (1991) 56.

[2] M. Monthioux, V. Kuznetsov, Carbon 44 (2006) 1621.

[3] P. J. F. Harris, Carbon Nanotube Science - Synthesis, properties and applications, Cambridge University Press, Cambridge, 2009.

[4] P. M. F. J. Costa, M. L. H. Green, Química 88 (2003) 57.

[5] ISI Web of Knowledge (Thomson Reuters), acessivel em: www.isiknowledge.com/

[6] Free Patents Online (freepatentsonline. com), acessível em: http://www.freepatentsonline.com/

[7] A. Jorio, M. Dresselhaus, G. Dresselhaus, eds., Carbon Nanotubes: Advanced Topics in the Synthesis, Structure, Properties and Applications, Springer, Heidelberg, 2007.

[8] P. M. Ajayan, S. lijima, Nature 358 (1992) 23.

[9] H. Kroto, J. Heath, S. O'Brien, R. Curl, R. E. Smalley, Nature 318 (1985) 162.

[10] R. H. Baughman, A. A. Zakhidov, W. A. de Heer, Science 297 (2002) 787.

[11] P. Serp, J. L. Figueiredo, Carbon 34 (1996) 1452

\section{Actualidades Científicas}

\section{JOYSTICK CELULAR}

Os cientistas sabem desde há décadas que as proteínas podem ser acetiladas em resíduos de lisina, mas esta modificação sempre foi vista como o parente pobre da fosforilação, que pode activar ou desactivar inúmeros processos em células vivas. No entanto, um novo estudo revela que a acetilação funciona também como um interruptor para um conjunto de funções celulares em organismos tão diversos como bactérias e humanos.

A acetilação é provavelmente mais conhecida pelo papel que desempenha no controlo dos genes de uma célula que são armazenados e que são sujeitos a transcrição. As primeiras pistas da sua versatilidade foram for- necidas no ano passado, quando uma equipa de investigadores, incluindo Churaram Choudhary, um bioquímico da Universidade de Copenhaga, descobriu que centenas de proteínas são acetiladas, incluindo algumas envolvidas na divisão celular e na reparação de ADN. Mais recentemente, Guo-Ping Zhao da Universidade de Fudan, Xangai, e Kun-Liang Guan, presentemente na Universidade da Califórnia, San Diego, revelaram que a acetilação controla a glicólise, os ciclos do ácido tricarboxílico e da ureia e os metabolismos dos ácidos gordos e do glicogénio (Science 327 (2010) 1000 e 1004). "Estes são os mecanismos fundamentais numa célula, como a célula obtém a sua energia", refere Choudhary. "A acetilação é uma forma muito elegante e precisa para as cé- lulas responderem e se adaptarem à energia que têm disponível", explica Zhao. Por exemplo, a equipa de investigadores descobriu que a acetilação permite às bactérias escolherem entre os mecanismos da glucose e do citrato, e às células do fígado humano escolherem entre os mecanismos da glucose e dos aminoácidos. A acetilação surge assim como um rival da fosforilação, pelo que é de todo pertinente descobrir como é que estes dois interruptores de controlo celular podem ser aproveitados em conjunto no desenvolvimento de fármacos com estas funcionalidades.

\section{(Adaptado de Chemical \& Enginee- ring News 88 (8) (2010) 11)}

\section{Helder Gomes}

\section{A NOVA FACETA DA RESISTÊNCIA AOS ANTIBIÓTICOS}

Quando os médicos receitam um antibiótico insistem com os pacientes para que o tomem na sua totalidade, de modo a prevenir a resistência ao fármaco que as bactérias conseguem desenvolver quando a dose é demasiado fraca.

Um novo estudo mostra agora que a administração inadequada de doses de um determinado antibiótico potencia a resistência, não só a esse antibiótico, mas também a outros antibióticos.
O estudo salienta a ocorrência de danos no ADN e de propensão de erros na sua reparação, como as causas.

O trabalho pode ajudar os cientistas a desenvolverem novas estratégias para combater o problema crescente da resistência aos antibióticos. O número de bactérias resistentes aos antibióticos tem crescido na última década.

O professor de engenharia biomédica James J. Collins e colaboradores da Universidade de Boston descobriram que a resistência pode ser desenvolvida quando radicais oxidantes (como o radical hidroxilo) gerados pela administração do fármaco danificam o ADN da bactéria. Embora o sistema de reparação do ADN frequentemente repare o dano no ADN, esta reparação é propensa a erros e pode gerar mutações aleatórias que afectam a resistência das bactérias (Mol. Cell, doi: 10.1016/j.molcel.2010.01.003).

A resistência pode ser desenvolvida não só ao agente administrado, mas também a outros agentes não administrados, podendo inclusive dar-se a situação em que a resistência é desenvolvida a agentes não administrados e não ao próprio agente administrado. 
Por exemplo, uma dose fraca de ampicilina pode potenciar a mutação da bactéria tornando-a resistente a um grande número de antibióticos, mas não à ampicilina. Os estudos de resistência a doses fracas de antibióticos têm incidido geralmente sobre a resistência aos agentes administrados e não a outros agentes não administrados.
As nova descoberta alerta para a necessidade de regular de uma forma mais apertada o uso de antibióticos, principalmente para sensibilizar os médicos a serem mais disciplinados na sua prescrição de antibióticos e os pacientes a serem mais disciplinados no cumprimento das suas prescrições. A co-administração de inibidores de sistemas de reparação de ADN (para prevenir os erros de reparação de ADN que causam mutações) pode ajudar a resolver este problema, refere Collins.

(Adaptado de Chemical \& Engineering News 88(8) (2010) 10)

Helder Gomes

\section{ESCLARECIMENTO DOS EFEITOS TRÁGI- COS DA TALIDOMIDA}

A talidomida foi usada para combater a lepra. Como consequência do seu uso, foram contabilizados nos anos de 1950 e 1960 cerca de 10000 a 20000 recém-nascidos com várias deficiências, em particular ao nível de malformações dos membros.

A explicação molecular para os efeitos da talidomida, enquanto fármaco de combate da lepra ou como sedativo e, sobretudo, o seu efeito no desenvolvimento dos membros dos fetos humanos, permanece, no entanto, por esclarecer. Os efeitos da talidomida são difíceis de estudar, dado que no organismo ambos os enantiómeros da talidomida são hidrolizados, hidroxilados e racemizados e estes percursos metabólicos variam em diferentes organismos. A talidomida afecta os fetos humanos e também provoca mal formações em recém-nascidos de galinhas e peixes, mas não em ratos.

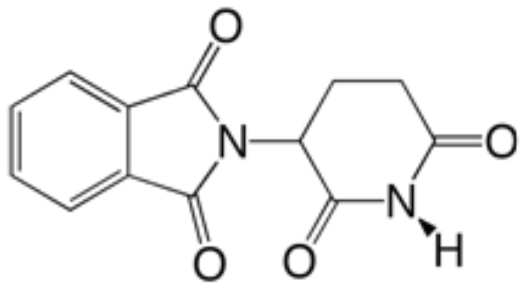

Talidomida

Tinham já sido publicados estudos que mostram que a talidomida bloqueia o desenvolvimento de vasos sanguíneos. Agora, uma equipa de investigadores japonesa identificou uma proteína humana que se liga à talidomida, designada por CRBN, e que faz parte de um complexo que degrada proteínas (Science 327 (2010) 1345). Esta equipa administrou talidomida a galinhas e peixes zebra que foram "modificados" para expressarem proteínas CRBN incapazes de se ligarem ao fármaco e verificaram que estes animais não exibiam mal-formações nos recémnascidos tão severas como acontecia com animais de controle.
Este trabalho é considerado uma peça importante do puzzle da talidomida, podendo vir a contribuir para o esclarecimento dos seus efeitos. Contudo, há ainda muitas outras proteínas às quais a talidomida se pode ligar e que falta identificar, em particular aquelas envolvidas na acção terapêutica da talidomida.

(Adaptado de C\&EN de 11 de Março)

JM

\section{NoVO SUPERCONDUTOR ORGÂNICO}

A supercondutividade caracteriza-se pela ausência de resistência eléctrica (não há efeito de Joule e, por isso, não podem ser usados como elementos de aquecimento eléctrico, podendo transportar corrente eléctrica sem perdas) e pelo seu diamagnetismo (repulsão dos campos magnéticos, sendo usado na levitação magnética).

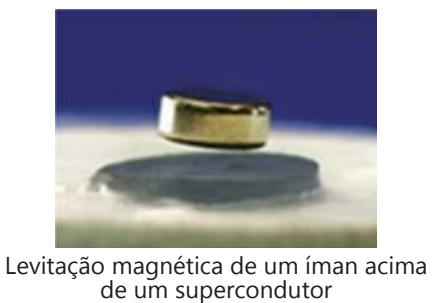

Os materiais supercondutores são usados no fabrico de magnetos potentes, como os utilizados no LHC (Large Hadron Collider), o maior acelerador de partículas do mundo localizado no CERN, e que recentemente retomou o seu funcionamento. Contudo a estabilização deste estado supercondutor exige a utilização de temperaturas baixas. Daí que haja um intenso trabalho de investigação que procura estabilizá-lo a temperaturas elevadas, idealmente próximas da temperatura ambiente. Após a descoberta da supercondutividade no mercúrio, por Heike Kamerlingh Onnes, na sequência do seu sucesso em liquefazer o hélio, em 1908, o mesmo comportamento foi descoberto noutros metais e ligas metálicas. A temperatura abaixo da qual se estabiliza o estado supercondutor designa-se por temperatura crítica, $\mathrm{T}_{\mathrm{c}}$. Além dos sistemas metálicos, a supercondutividade foi também descoberta em materiais cerâmicos (sendo nesta altura os materiais que exibem o valor mais alto de $T_{c}$, da ordem dos $120 \mathrm{~K}$ ), e também em sistemas de base orgânica. A supercondutividade em sistemas orgânicos foi inicialmente descoberta no sal (TMTSF) ${ }_{2} \mathrm{PF}_{6}$ (família de compostos conhecida como "sais de Bechgaard"), inicialmente com $T_{c} \approx 0,9$ K, sob pressão de 6500 bar, e o valor da temperatura crítica foi rapidamente aumentando até cerca de $12 \mathrm{~K}$ à pres- 
são atmosférica, por variações moleculares.<smiles>CC1=C(C)[Se]C(=C2[Se]C(C)=C(C)[Se]2)[Se]1</smiles>

Molécula de tetrametiltetrasselenafulvaleno, TMTSF

Um (e único) polímero supercondutor, (SN)x, foi também identificado.

A supercondutividade foi também descoberta em fulereno dopado com metais alcalinos (como $\mathrm{K}_{3} \mathrm{C}_{60}, \mathrm{~T}_{\mathrm{c}}=18$ $\mathrm{K})$ e em grafite intercalada com cálcio $\left(T_{c}=11 \mathrm{~K}\right)$.

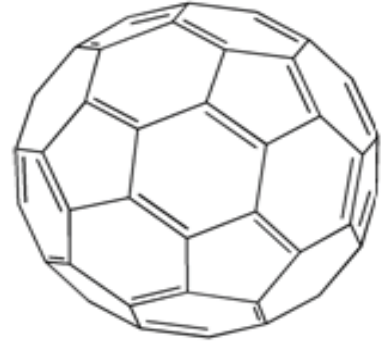

Molécula de fulereno $\mathrm{C}_{60}$.

A última descoberta de um supercondutor de base orgânica foi feita por uma equipa japonesa, liderada por Yoshihiro Kubozono, prof. da Universidade de Okayama. O material em causa é o piceno, uma subunidade do grafeno, dopado com átomos de potássio ou de rubídeo, que se tor- na supercondutor a $18 \mathrm{~K}$ (Nature 464 (2009) 76). Apesar do valor de $T_{c}$ ser muito baixo, e comparável ao obtido para outros supercondutores orgânicos, esta descoberta pode levar à preparação de novos supercondutores.

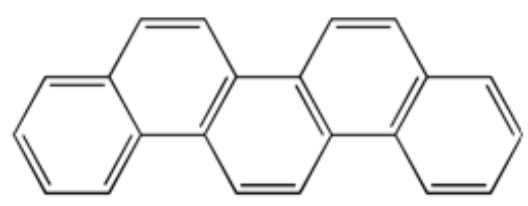

Molécula de piceno

(Adaptado de C\&EN de 8 de Março)

JM

\section{ESTRUTURA DO IÃO HIDROGÉNIO EM ÁGUA $\left(\mathrm{H}_{\mathrm{aq}}{ }^{+}\right)$}

A descrição molecular correcta do ião hidrogénio $\mathrm{H}_{\mathrm{aq}}{ }^{+}$em água, produzido pela dissociação de um ácido, tem sido uma das questões mais antigas em Química. Apesar de vulgarmente se considerar que a espécie formada é $\mathrm{H}_{3} \mathrm{O}_{\text {aq }}{ }^{+}$, considerando uma descrição mais genérica $\mathrm{H}\left(\mathrm{H}_{2} \mathrm{O}\right)_{n}{ }^{+}$, o valor de $n$ tem sido objecto de longo debate, não estando bem definido. Em particular, tem havido grande debate sobre a importância relativa das estruturas dos tipos Eigen, $\mathrm{H}_{3} \mathrm{O}^{+} \cdot 3 \mathrm{H}_{2} \mathrm{O}(\mathrm{I})$, ou Zundel, $\mathrm{H}_{5} \mathrm{O}_{2}^{+}$(II):
Um grupo da Universidade da Califórnia em Riverside (Journal of the American Chemical Society 132 (2010) 1484), mostrou agora, com base num estudo de espectroscopia de infravermelho (IV) para soluções aquosas de ácidos fortes, que a descrição adequada de $\mathrm{H}_{\mathrm{aq}}{ }^{+}$requer a sua escrita formal como um ião $\mathrm{H}\left(\mathrm{H}_{2} \mathrm{O}\right)_{6}{ }^{+}$. O espectro de IV deste ião não corresponde a nenhum dos tipos de estrutura acima descritos (Eigen ou Zundel). Para explicar a diferença entre esta estrutura e a de Eigen distorcida $\mathrm{H}\left(\mathrm{H}_{2} \mathrm{O}\right)_{4}{ }^{+}$que é a mais favorável, segundo os estudos teóricos, os autores propõem que o encurtamento de uma das ligações<smiles></smiles>

Recentes estudos teóricos favorecem uma descrição cinética que esbate a distinção entre estas duas estruturas estáticas. O mínimo de energia foi calculado como correspondendo a uma estrutura do tipo Eigen (I), distorcida, em que uma das ligações de hidrogénio assimétricas $\mathrm{O}-\mathrm{H} \cdot \cdots \cdot \mathrm{O}$ ("par especial") é mais curta que as outras duas. de hidrogénio $\mathrm{O}-\mathrm{H}-\cdots \cdot \mathrm{O}$ em I para criar o "par especial" atrai mais duas moléculas de água da vizinhança exterior para junto do núcleo da estrutura de Eigen, convertendo-a num ião $\mathrm{H}_{(}\left(\mathrm{H}_{2} \mathrm{O}\right)_{6}{ }^{+}$. A carga positiva do ião estende-se até aos átomos de oxigénio da camada de hidratação exterior, mas não de forma significativa que permita distinguir as frequências de vibração de $\mathrm{OH}$ em relação às da água "pura". É assim proposta a estrutura III para este catião, em que o círculo a tracejado que passa pelos átomos de O da camada de hidratação exterior define a extensão da deslocalização da carga positiva, consistente com a formulação $\left.\mathrm{H}_{(} \mathrm{H}_{2} \mathrm{O}\right)_{6}{ }^{+}$:

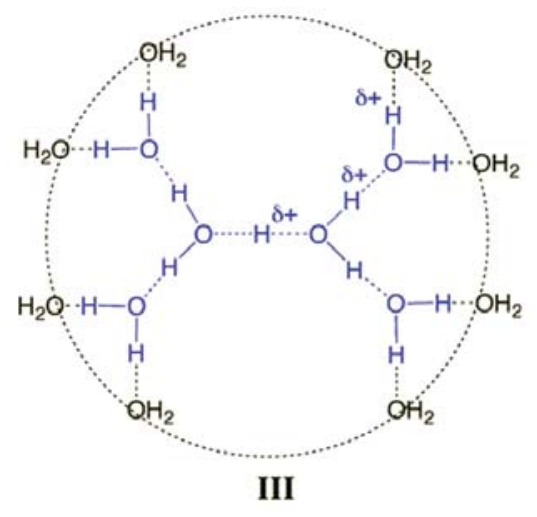




\section{Actualidades Científicas}

\section{Células solares de corante ou cé-} LULAS DE GRäTZEL

\section{Sobre a necessidade}

O desenvolvimento das células solares está a ser promovido pela crescente preocupação de as reservas de petróleo poderem esgotar-se neste século e ainda sobre o impacto ambiental resultante do seu uso. É previsível que as necessidades energéticas do planeta dupliquem nos próximos 50 anos, pelo que se torna necessário desenvolver fontes de energia renovável que compensem o défice resultante da utilização dos combustíveis fósseis.

Entre as fontes possíveis, o Sol constitui uma das mais apelativas: a energia recebida pela Terra proveniente do Sol atinge $3 \times 10^{24}$ joules por ano, ou seja, cerca de 10000 vezes mais do que o consumo actual pela população global. Assim, cobrindo cerca de 0,1\% da superfície da Terra com células solares com eficiência de $10 \%$ seria suficiente para suprir as necessidades actuais. Contudo, conseguir aceder a este enorme reservatório de energia permanece um desafio enorme.

\section{A figura 1 mostra o espectro solar.}

A eficiência das células solares é determinada não só por parâmetros intrínsecos (eficiência dos processos de absorção de fotões, eficiência de conversão em carga eléctrica e eficiência de recolha dessa carga) mas também pela gama de comprimentos de onda que conseguem absorver e converter em energia eléctrica. Note-se que a gama do visível (400-750nm) corresponde apenas a cerca de $490 \mathrm{~W} / \mathrm{m}^{2}$, ou seja, cerca de metade da energia total recebida do Sol. Refira-se, por outro lado que, se toda a energia solar fosse convertida em energia eléctrica, a corrente máxima gerada (em circuito fechado) seria de $68,9 \mathrm{~mA} / \mathrm{cm}^{2}$.

Para optimizar a eficiência desta conversão energética, estão em desenvolvimento concentradores solares que, absorvendo uma gama mais larga de comprimentos de onda, convertem essa energia numa gama de comprimentos de onda mais estreita que se procura depois combinar com células solares que exibam máxima eficiência de conversão energética nessa região espectral.

\section{Sobre as abordagens}

As células fotovoltaicas usam o facto de a absorção de fotões na gama do ultravioleta e do visível provocar excitações electrónicas. Numa molécula, a transição electrónica de menor energia envolve a excitação de um electrão da HOMO (highest occupied molecular orbital ou orbital ocupada de mais alta energia) para a LUMO

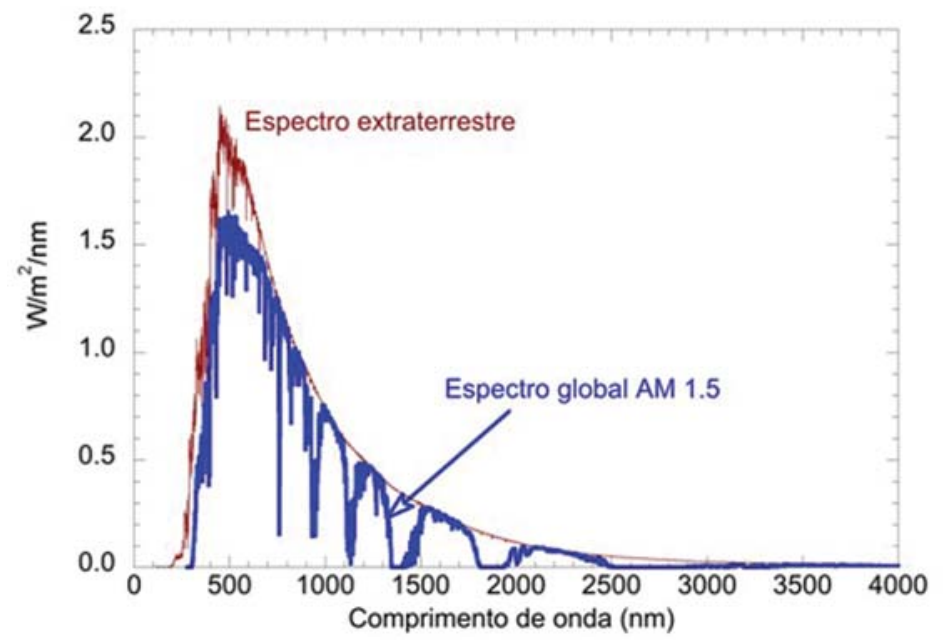

Figura 1 Espectro solar extraterrestre (densidade de energia total de $1366 \mathrm{~W} / \mathrm{m}^{2}$ ) e espectro global AM1.5, que corresponde ao espectro à superfície da terra (depois de atravessar a atmosfera) obtido quando o sol incide a $48^{\circ}$ em relação ao zénite (a densidade de energia total é de $1000 \mathrm{~W} / \mathrm{m}^{2}$ )

(lowest unoccupied molecular orbital ou orbital vazia de menor energia).

O electrão promovido para a LUMO e o buraco que ficou na HOMO constituem um par electrão-buraco (de carga total nula). Num semicondutor inorgânico, este par descreve-se como uma carga negativa na banda de valência e uma carga positiva na banda de condução, com fraca ligação entre elas e podendo estar espacialmente afastadas.

Em sistemas moleculares, este par está mais fortemente ligado, estando as duas cargas muito próximas. Para conseguir separar estas duas cargas, recorre-se a junções de dois materiais.

A ciência das células solares tem sido dominada por dispositivos em que esta junção envolve semicondutores inorgânicos no estado sólido, habitualmente formas dopadas de silício amorfo ou cristalino e outros semicondutores compostos, tirando também partido da experiência e materiais disponibilizados pela indústria dos semicondutores.

Também os semicondutores orgânicos, quer moléculas de baixo peso molecular quer polímeros conjugados, têm estado a desenvolver-se.

As células orgânicas de polímero com maior eficiência (ca. $6 \%$ de conversão energética) são as baseadas no poli(hexiltiofeno), como doador electrónico, e em fulerenos $\left(C_{60}, C_{70}\right.$ e formas solúveis), como aceitadores electrónicos. Foi anteriormente referido (Química, vol 106, Jul/Set 2007) de forma sumária, o funcionamento das células fotovoltaicas de polímeros conjugados luminescentes combinados com fulerenos, funcionando o polímero como doador electrónico e o fulereno como aceitador.

Neste caso, após absorção de luz (primordialmente pelo polímero conjugado luminescente), dá-se, durante o tempo de vida do estado excitado (da ordem de nanosegundos), uma 
transferência de carga entre os dois componentes que, ao serem separadas (carga positiva ou buraco no polímero conjugado e electrão no fulereno) para cada um dos eléctrodos podem ser usadas para realizar trabaIho eléctrico (accionando dispositivos eléctricos).

Contudo, é também possível usar não uma junção sólida, mas uma junção sólido-líquido, em que a fase sólida é constituída por um semicondutor e a fase líquida é um electrólito, obtendo-se uma célula fotoelectroquímica [1]. O electrólito pode ainda apresentar-se sob a forma de um gel ou como um electrólito sólido.

\section{Sobre as células de corante (DSCs)}

As células fotovoltaicas sensibilizadas com corante (Dye Sensitized Solar Cells, DSCS) foram inventadas por Michael Grätzel em 1991.

No essencial combinam elementos activos orgânicos e inorgânicos e são, a par das células fotovoltaicas orgânicas (de polímero ou com base em moléculas de baixo peso molecular), a alternativa às células fotovoltaicas inorgânicas (com base em silício e outros semicondutores inorgânicos elementares ou compostos).

Para se conseguir a absorção de energia e a separação de carga, há uma associação de um sensibilizador, como material absorvedor de fotões, com um semicondutor de hiato grande com morfologia mesoporosa ou nanocristalina. O sensibilizador, fotonicamente excitado, transfere o electrão promovido à sua LUMO para a banda de condução do óxido semicondutor. O buraco que fica na HOMO é depois transferido para o cátodo (usualmente de platina), sendo este transporte mediado por um par redox dissolvido num electrólito que põe em contacto as nanopartículas do óxido e o cátodo. Este transporte de buracos pode, em alternativa, ser descrito como um transporte de electrões do cátodo para a HOMO do corante semi-ocupada, mediado pelo par redox referido. Desta forma recupera-se o corante no estado fundamental e disponível para sofrer nova excitação.

\section{Sobre o funcionamento das DSCs}

O princípio de operação de uma DSC resume-se na figura 2. No centro destas células está um filme mesoscópico de um óxido semicondutor que é colocado em contacto com um electrólito contendo um par redox ou em contacto com um condutor de buracos. a maximizar a absorção de fotões. A fotoexcitação deste corante resulta na injecção de um electrão na banda de condução $(\mathrm{BC})$ do óxido. O corante é regenerado através da doação de um electrão pelo electrólito (habitualmente um líquido orgânico contendo um sistema redox, como o par iodeto/ tri-iodeto).

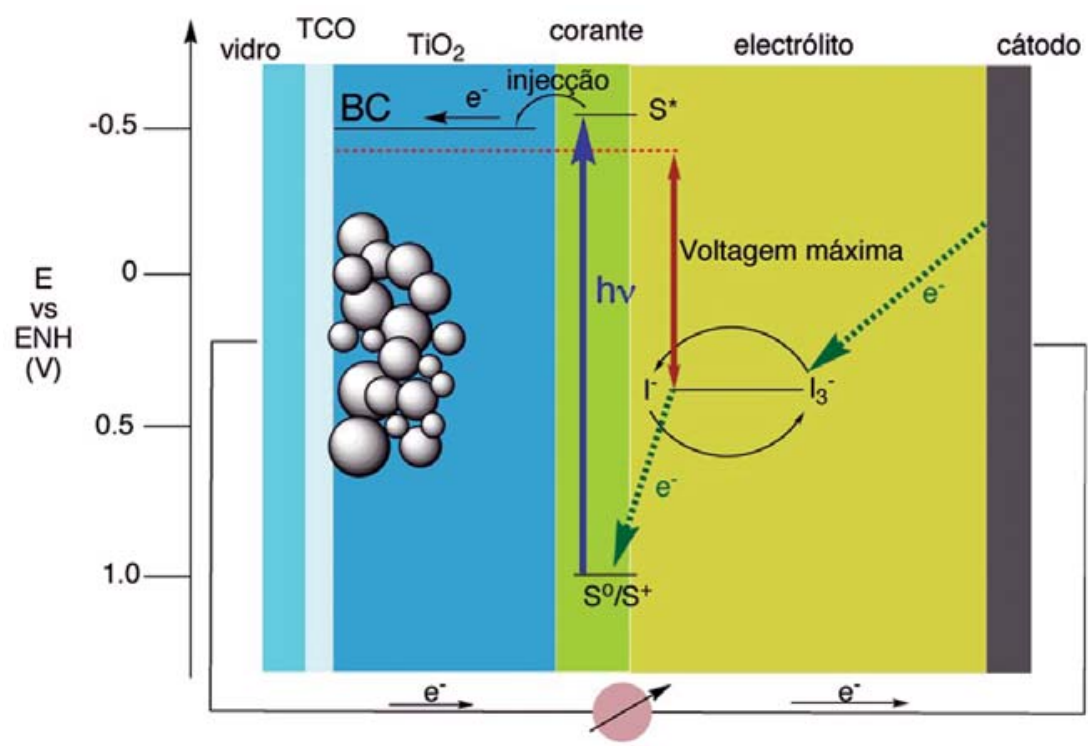

Figura 2 Esquema de funcionamento de uma DSC (adaptado de [2,3]) evidenciando a excitação electrónica do corante, a transferência electrónica do estado excitado para a banda de condução (BC) do $\mathrm{TiO}_{2}$ e a transferência electrónica do mediador ( $\mathrm{I}^{-}$), que se oxida a $\mathrm{I}_{3}$, para o corante, com a recuperação da forma reduzida por redução do $\mathrm{I}_{3}^{-}$no cátodo. A difusão do $\mathrm{I}_{3}$ ' para o cátodo contribui para o controle cinético do funcionamento da DSC. TCO designa um óxido condutor transparente (como ITO-indium-tin oxide, ou FTO-fluorinated tin oxide). São apresentados os potenciais em relação ao eléctrodo normal de hidrogénio (ENH)

O óxido semicondutor mais usado é o $\mathrm{TiO}_{2}$ (anatase), com um hiato de 3,2 $\mathrm{eV}$, embora outros óxidos de grande hiato, como $\mathrm{ZnO}$ e $\mathrm{Nb}_{2} \mathrm{O}_{5}$, tenham também sido estudados. Tendo um hiato elevado, significa que estes óxidos absorvem essencialmente na região do ultravioleta.

Os filmes de óxidos mesoporosos são constituídos por empacotamento de pequenos cristais com alguns nanómetros de dimensão. Estes cristais estão interligados, permitindo a condução electrónica. São habitualmente preparados por técnicas de sol-gel ou depositados por outras técnicas, havendo um passo final de recozimento acima de $400^{\circ} \mathrm{C}$.

À superfície do filme nanocristalino de óxido encontra-se ligada uma monocamada de um corante sensibilizador, desenhado para absorver radiação a comprimentos de onda aos quais os óxidos são transparentes, de modo
A regeneração do corante pelo iodeto impede a recaptura do electrão, que se encontra na banda de condução, pelo corante oxidado. Por sua vez, o iodeto é regenerado pela redução de tri-iodeto no contra-eléctrodo, sendo o circuito fechado através da migração de electrões no circuito externo.

A tensão gerada sob iluminação corresponde à diferença entre o nível de Fermi do electrão no sólido e o potencial redox do electrólito.

Este dispositivo gera assim energia eléctrica a partir de energia solar sem sofrer nenhuma transformação química permanente.

No primeiro dispositivo preparado no laboratório foi usada uma folha de titânio recoberta com um filme fractal de $\mathrm{TiO}_{2}$ de elevada área superficial produzido por sol-gel. A superfície foi derivatizada com um corante amarelo de ruténio, $\mathrm{RuL}_{3}$ ( $L=2,2$ '-bipiridil-4,4- 
-dicarboxilato). Como contra-eléctrodo foi usado um fio de platina. O copo contendo estes dois componentes foi enchido com uma solução aquosa de electrólito, ligeiramente acidificada, contendo brometo e uma pequena quantidade de bromo. A tensão de circuito aberto conseguida por iluminação com uma lâmpada de halogéneo foi de $1 \mathrm{~V}$. A eficiência de conversão energética, quando exposta à luz solar, era de 1 a $2 \%$.

O transporte electrónico através da banda de condução do filme de óxido mesoscópico está acoplado com reacções de transferência electrónica e com a difusão iónica através do electrólito.

Em particular, o movimento de electrões na banda de condução do filme de óxido semicondutor é acompanhado pela difusão de catiões na camada de electrólito junto à superfície das nanopartículas, para compensar a carga.

Sobre a captura de luz pelos filmes de óxido mesoporosos derivatizados com corante

A absorção de luz por uma monocamada de corante é muito pequena, pelo que para se obter uma significativa eficiência fotovoltaica não se pode usar uma superfície plana de semicondutor. Daí a utilização de filmes porosos e nanoestruturados, com elevada área superficial. O filme nanoestruturado tem também que servir como condutor electrónico.

O sensibilizador, electronicamente excitado, transfere um electrão para a BC do óxido semicondutor de hiato elevado. Os electrões têm depois que se movimentar rapidamente através dos caminhos de percolação da camada de $\mathrm{TiO}_{2}$.

Um dos requisitos para a implementação real destes dispositivos é um longo tempo de vida, sem perda de performance. Muito trabalho tem sido dedicado ao desenvolvimento de compostos de ruténio, que são conhecidos pela sua excelente estabilidade.

Na figura 3 mostram-se as estruturas de alguns destes compostos.

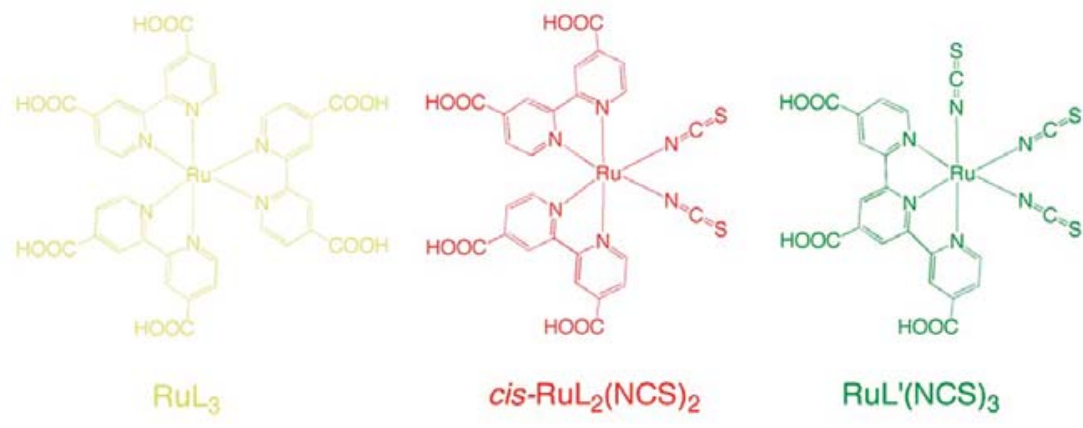

Figura 3 Estrutura de alguns complexos de ruténio usados como sensibilizadores em DSCs ( $L=$ =ácido 2,2'-bipiridil-4,4'-dicarboxílico, L'=ácido 2,2',2"'-terpiridil-4,4',4"'-tricarboxílico)

Os filmes constituídos por nanopartículas de óxido constituem uma abordagem simples e muito poderosa para conseguir uma absorção eficiente de luz pela monocamada de moléculas de corante adsorvidas à superfície. Outras abordagens para aumentar a eficiência de captura de fotões incluem a localização de luz e a utilização de efeitos de hiato fotónico.

Para conseguir uma elevada eficiência de conversão energética, os corantes devem possuir grupos de ancoramento à superfície do óxido, como carboxilatos, hidroxamatos ou fosfonatos. Estes grupos deve ainda promover um forte acoplamento electrónico entre a LUMO dos corantes e a $\mathrm{BC}$ do semicondutor.

Pontos quânticos (quantum dots, QDs) podem substituir os corantes como unidades de captura dos fotões em DSCs. A absorção de luz cria excitões ou pares electrão-buraco nos QDs. O electrão é depois injectado na BC do óxido semicondutor enquanto que $\mathrm{O}$ buraco é transferido para um condutor de buracos ou para um electrólito presente nos poros do filme de óxido nanocristalino. Foi já demonstrada uma eficiente e rápida injecção de buracos de QDs de PbS para triarilaminas, que são materiais condutores de buracos. Os QDs podem efectuar a captura de fotões de forma mais eficiente do que os corantes mas ocupam uma área superior, reduzindo por isso a sua concentração comparativa.

\section{Sobre o electrólito}

Além dos electrólitos líquidos, têm sido estudados géis e electrólitos poliméricos. A utilização de líquidos implica um cuidadoso trabalho de selagem da célula para evitar a fuga do líquido, o que se procura evitar recorrendo a electrólitos sólidos.

Os electrólitos poliméricos são constituídos por misturas de um polímero com um sal iónico. Pretende-se maximizar a condutividade eléctrica por iões, mantendo a condutividade electrónica a valores desprezáveis.

O polímero, possuidor de átomos com pares electrónicos isolados ( $\mathrm{N}$ e $\mathrm{O}$, por exemplo), funciona como solvente sólido, solvatando os catiões de um sal, promovendo a sua dissociação. O poli(óxido de etileno), PEO, $\left(\mathrm{CH}_{2} \mathrm{CH}_{2} \mathrm{O}\right)_{n}$, tem sido dos mais usados, pois possui baixa temperatura de transição vítrea, $T_{g}$, de cerca de - $50^{\circ} \mathrm{C}$, sendo contudo um polímero com elevada percentagem de cristalinidade (tipicamente da ordem de $80 \%$ ), a que corresponde uma temperatura de fusão de $\sim 65^{\circ} \mathrm{C}$.

Este aspecto é relevante pois a migração iónica está associada a movimentação molecular de segmentos de PEO, estando por isso limitada aos domínios amorfos. A coordenação dos catiões pelos átomos de $\mathrm{O}$ da cadeia conduz, por outro lado, a um aumento de $T_{g}$.

Para contrariar este efeito procede-se à adição de plastificantes. A utilização de misturas de polímeros e de copolímeros tem também sido explorada. A utilização destes electrólitos em DSCs tem a grande limitação de conduzir a uma fraca penetração na região livre dos filmes nanoporosos dos óxidos semicondutores, limitando a performance das DSCs. A utilização de várias técnicas de deposição tem no entanto permitido resultados interes- 
santes com estes sistemas.

Sobre as estruturas mais recentes

O corante mais usado tem sido o cis-Ru(NCS) ${ }_{2} \mathrm{~L}_{2}$ (L=2,2'-bipiridilo-4,4'-dicarboxilato), designado abreviadamente por N3. O sistema redox mais usado para regenerar o corante e transportar as cargas positivas para o contra-eléctrodo tem sido o par iodeto/tri-iodeto dissolvido num electrólito orgânico ou num líquido iónico.

Por iluminação com luz solar total ( $A M$ $1.5 \mathrm{global}$, intensidade de 1000W/ $\mathrm{cm}^{2}$ ) têm sido obtidos valores de fotocorrente em circuito fechado de 16 a $22 \mathrm{~mA} / \mathrm{cm}^{2}$ e tensões em circuito aberto de 0.7-0.86V. Valores de eficiência de conversão energética da ordem de $11 \%$ foram já obtidos. Um teste de tempo de vida por exposição contínua a luz de intensidade total durante $12000 \mathrm{~h}$ foi recentemente efectuado, que confirmou que este sistema não sofre de qualquer instabilidade inerente, ao contrário do que acontece com o silício amorfo que sofre fotodegradação.

\section{Perspectivas}

A performance fotovoltaica das DSCs depende do posicionamento relativo dos níveis energéticos e da cinética dos processos de transferência electrónica nas interfaces. De forma a melhorar a eficiência e facilitar a aplicação das DSCs, os desafios que se apresentam são a optimização conjunta dos diversos componentes e o desenvolvimento de novas técnicas para melhorar o controle da cinéticas dos processos de transferência de carga nas interfaces.

Refira-se que as DSCs têm suscitado interesse industrial, tendo sido já produzidas telhas para testes de campo.

\section{REFERÊNCIAS}

[1] M. Grätzel, Nature 414 (2001) 338-344 .

[2] M. Grätzel, Inorganic Chemistry 44 (2005) 6841-6851.

[3] B. O'Regan e M. Grätzel, Nature 353 (1991) 737-740.

[4] Y. Luo, D. Li e Q. Meng, Advanced Materials 21(2009) 4647-4651.

[5] J. N. de Freitas, A. F. Nogueira e M.-A. de Paoli, Journal of Materials Chemistry 19 (2009) 5279-5294 .

\section{Jorge Morgado}

\section{UM TRICICLO AROMÁTICO ISÓMERO DO HEXASILABENZENO}

O benzeno é o protótipo dos compostos aromáticos, estabelecendo a base da famosa regra associada a Hückel de que a presença de $4 n+2$ electrões deslocalizados em ciclo identifica a aromaticidade e a estabilização associada.

A perspectiva de conseguir compostos aromáticos à base de silício (pertencente ao mesmo grupo da Tabela Periódica que o carbono) foi ignorada durante muito tempo dado que o silício tem sido considerado genericamente incapaz de formar ligações $\pi$ estáveis. Contudo, desde 1981 que se obtiveram vários compostos de silício em que este forma ligações duplas ou triplas.

Tal resulta da estabilização electrónica ou estereoquímica (por exemplo usando substituintes volumosos como o mesitilo (2,4,6-trimetilfenilo)).
Em particular, foram preparados silae 1,2-disilabenzenos planares e com estruturas do tipo Hückel. A obtenção de sistemas aromáticos baseados apenas em silício tem sido mais difícil $\mathrm{e}$, em particular, o hexasilabenzeno $\left(\mathrm{Si}_{6} \mathrm{H}_{6}\right)$, não foi ainda preparado.

Recentemente (Science 327 (2010) 564) um grupo do Imperial College London conseguiu preparar e isolar cristais de $\mathrm{Si}_{6} \mathrm{R}_{6}$ (em que $\mathrm{R}=2,4,6$ - -triisopropilfenil), um isómero dismutal do hexasilabenzeno, com carácter aromático.

A estrutura, determinada por difracção de raios $X$, confirmou a conformação em cadeira prevista teoricamente para o hexasilabenzeno.

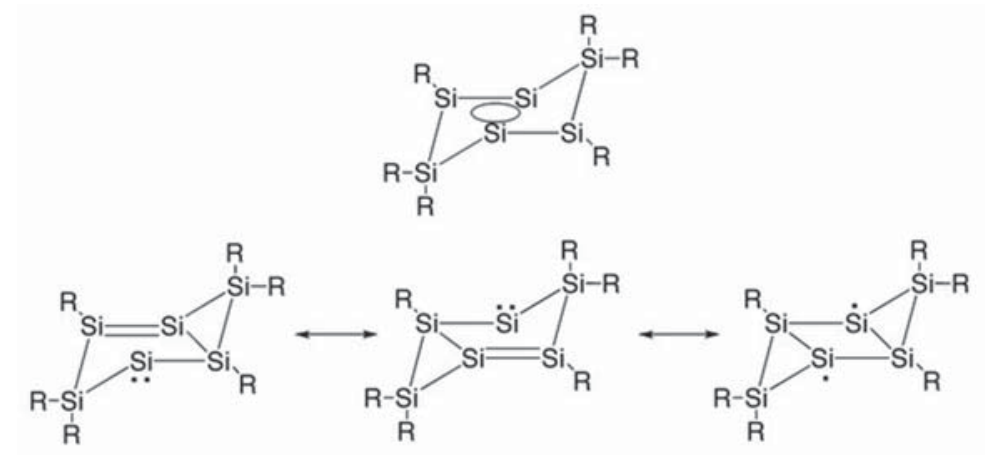




\section{(3)WILEY}

\section{Chemistry \& Sustainability, Energy \& Materials}

\section{To view the latest articles below, simply visit www.chemsuschem.org}

\section{Communications:}

$\varepsilon$-Caprolactamium Hydrogen Sulfate: An Ionic Liquid Used for Decades in the Large-Scale Production of $\varepsilon$-Caprolactam I. T. Horváth et al.

Highly Active Catalysts for the Telomerization of Crude Glycerol with 1,3-Butadiene

B. M. Weckhuysen et al.

Synthesis of Dimethyl Carbonate from Carbon Dioxide Catalyzed by Titanium Alkoxides with Polyether-type Ligands T. Sakakura et al.

A Versatile Iridium Catalyst for Aldehyde Reduction in Water J. Xiao et al.

\section{Full Papers:}

Surfactants from Biomass: A Two-Step Cascade Reaction for the Synthesis of Sorbitol Fatty Acid Esters Using Solid Acid Catalysts A. Corma et al.

Regiodivergent Baeyer-Villiger Oxidation of Fused Ketones by Recombinant Whole-Cell Biocatalysts M. D. Mihovilovic et al.

A Highly Active Aqueous Olefin Metathesis Catalyst Bearing a Quaternary Ammonium Group K. Grela et al.

On the Energy Efficiency of Microwave-Assisted Organic Reactions

C. O. Kappe et al.

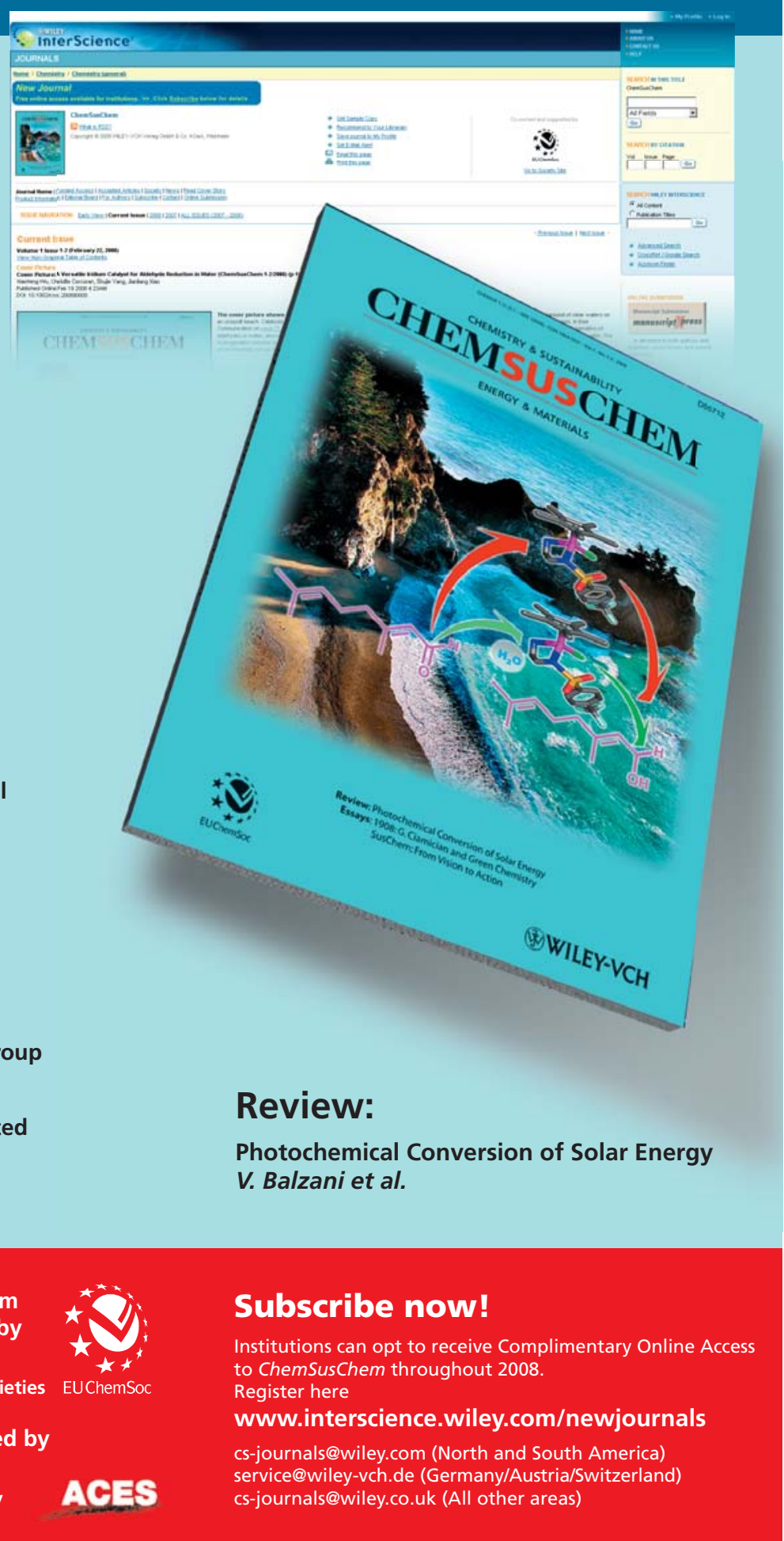

ChemSusChem is co-owned by Editorial Union of Chemical Societies and supported by Gesellschaft Deutscher Chemiker (GDCh)

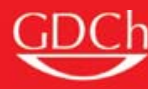

Asian Chemical Editorial Society

\section{Subscribe now!}

Institutions can opt to receive Complimentary Online Access to ChemSusChem throughout 2008. Register here

ww.interscience. cs-journals@wiley.com (North and South America) ce@wiley-vch.de (Germany/Austria/Switzerland) cs-journals@wiley.co.uk (All other areas) 